\title{
Dengue: Moving from Current Standard of Care to State- of-the-Art Treatment
}

\section{Victor C. Gan, MBBS}

\author{
Address \\ Institute of Infectious Disease and Epidemiology, Tan Tock Seng Hospital, \\ 11 Jalan Tan Tock Seng, Singapore 308433, Singapore \\ Email: Victor.Gan@mohh.com.sg \\ Published online: 17 July 2014 \\ (C) The Author(s) 2014. This article is published with open access at Springerlink.com
}

Keywords Dengue - Dengue hemorrhagic fever - Dengue shock syndrome - Warning signs - Severe dengue

\section{Opinion statement}

Treatment of dengue remains supportive in the absence of targeted antiviral therapy or approved vaccines. Responsive fluid management is key to preventing progression to shock or other severe manifestations. The dynamic natural history of dengue infection and its influence on hemodynamic homeostasis needs to be carefully considered in the planning of individualized therapy. Though largely self-limiting, the sheer burden of dengue disease on the global population will result in atypical manifestations especially in children, older adults, and comorbid patients. Management of these has not yet been systematized. The failure of recent randomized controlled trials to show utility for antiviral and immunomodulatory agents in dengue is disappointing. Vaccine candidates hold promise, but growing outbreaks require more robust, evidence-based management guidelines to inform clinicians, especially in novel epidemic situations.

\section{Introduction}

Dengue is caused by a flavivirus comprising four established serotypes (DENV1-4), with a fifth serotype recently proposed [1]. Dengue has the greatest reach of all arthropod-borne viral (arboviral) infections, with an estimated 390 million infections a year [2]. Dengue infection manifests with a variety of clinical syndromes, from asymptomatic infection, to undifferentiated acute febrile illness, to dengue hemorrhagic fever and severe dengue, including dengue shock syndrome [ $3 \bullet]$. Historically, dengue has been one of a number of mosquitoborne acute febrile illnesses, and differentiation from other flaviviruses such as yellow fever, alphaviruses such as chikungunya, or parasitic infections such as malaria has not always been possible when attributing etiologic agents to historic outbreaks from the late 18th century until the isolation of dengue virus in 1943 [4, 5].

One of the earliest accounts of what was then known as breakbone fever or Dandy fever was by Benjamin Rush, describing the outbreak in Philadelphia in 1780 [6]. He already recognized that the vast majority of patients recover without major complications after suffering for a few days of fevers and aches. He 
recommended bed rest (rather than exercise), and treated patients with emetics and laxatives following the practice of the day, along with opiates. He recognized the occasional complication from bleeding and warned against blood letting, otherwise a popular recourse. Similar treatment for this largely non-fatal fever continued to be recommended by physicians in the outbreaks of the early 19th century, for example in India [7], Zanzibar (Tanzania) [8], and South Carolina [9]. As one of many tropical fevers, generic folk remedies recorded historically and currently in vogue included porcupine bezoars [1012] and papaya leaf extract. Several publications examining the latter in the context of dengue infection have given equivocal results [13-16]. Into the early 20th century, treatment has remained supportive, primarily comprising analgesics and antipyretics for symptomatic relief, with the management of complications as they arise, such as bleeding, dehydration, shock, or organ failure.

The impact of dengue precipitously increased after World War II where a host of epidemiologic and ecologic factors affecting the spread of Aedes aegypti, urbanization trends, and increased global travel led to large pediatric epidemics with high mortality in southeast Asia [17] and later in the Americas [5]. The clinical experience derived from these epidemics allowed physicians to develop clinical protocols to reduce mortality, which were promulgated by the World Health Organization (WHO) [18]. The key intervention was understood to be intensive intravenous fluid administration to counteract the fluid leak from capillaries in the critical defervescent phase, when children in particular are prone to develop shock and organ failure. Development of the concept of dengue hemorrhagic fever as a syndromic precursor to shock and death led to an emphasis on identifying candidates for judicious rehydration by frequent monitoring of blood pressure, haematocrit, and signs of shock such as capillary refill and other signs of peripheral circulatory collapse. Implementation of standardized treatment guidelines led to a marked reduction in case fatality from over $13 \%$ to less than $0.1 \%$ in Thailand [19]. Increasing adherence to guidelines (primarily encouraging oral rather than intravenous fluid therapy where appropriate) has been shown to lead to gains in resource use in dengue case management without adversely affecting morbidity or mortality in Nicaragua [20]. The importance of optimizing guidelines locally has also been shown in Singapore, where significant cost savings were associated with reductions in unnecessary hospitalization after admission criteria were modified and more strictly enforced [21].

\section{Treatment guidelines}

Dengue management algorithms have been developed by the WHO South East Asia Regional Organization (SEARO) and the WHO Pan American Health Organization, which have been further adapted in national guidelines. The premise is distinction of dengue disease from other tropical fevers, for which clinical criteria alone are not sufficiently discriminatory, especially in older adults [22-24]. Diagnostic testing is strongly recommended, summarized in Table 1. In brief, in endemic areas or in likely immune populations with past exposure to dengue or other related flaviviruses, reverse transcriptionpolymerase chain reaction (RT-PCR) and non-structural protein 1 (NS1) detection are most useful because of their specificity, particularly in early presentation. In late presentation, clinical manifestations may have to guide management with a battery of repeated tests requiring evidence synthesis by experienced physicians to determine etiology. In travelers or other non-immune populations, in addition to RT-PCR and NS1 in the early or febrile phase, immunoglobulin M and immunoglobulin G may be more useful, but with caveats about accuracy. In the context of an acute undifferentiated tropical fever otherwise negative for common etiologic agents such as Plasmodium or Salmonella, the combination of leukopenia, severe thrombocytopenia $\left(<50000 / \mathrm{mm}^{3}\right)$, rapid changes in hematocrit ( $>20 \%$ change from baseline or initial value), and elevated 


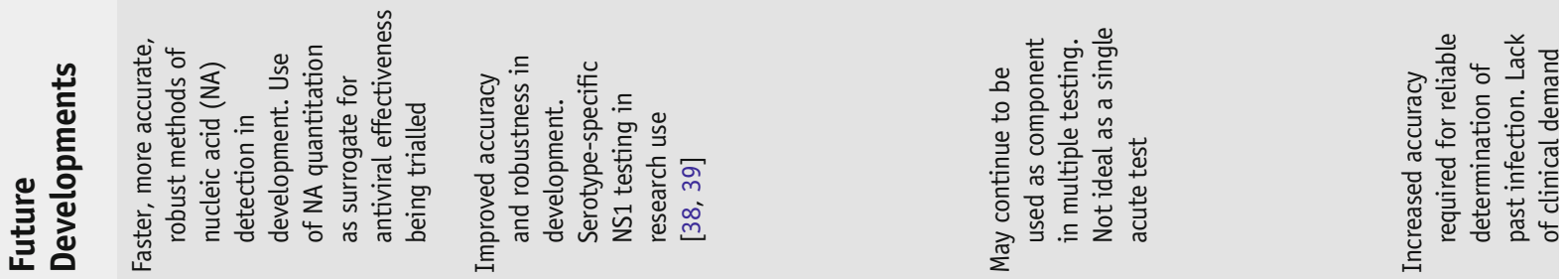

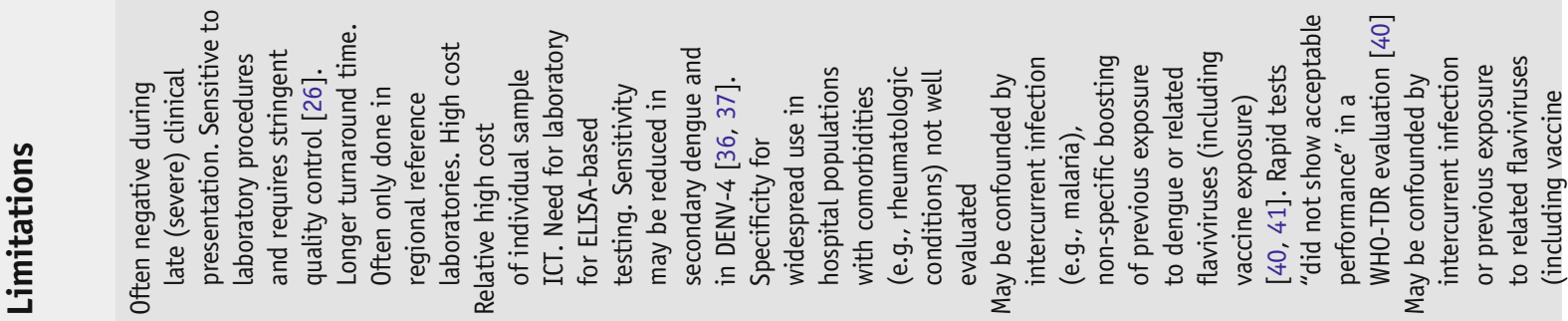

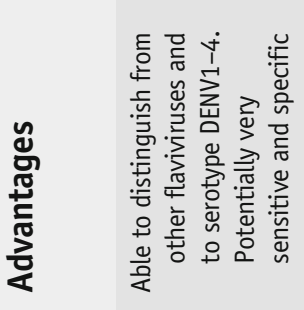
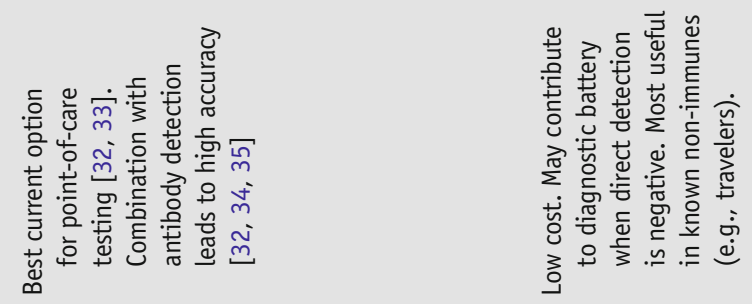

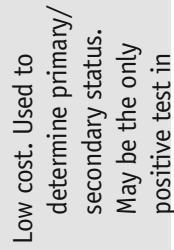

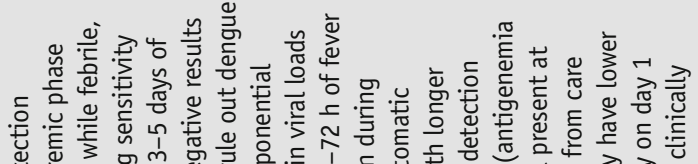

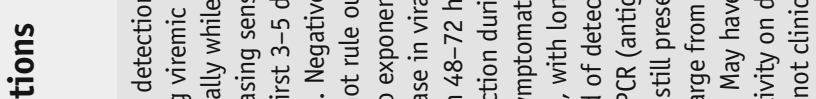

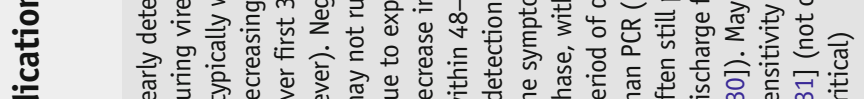

음 훈

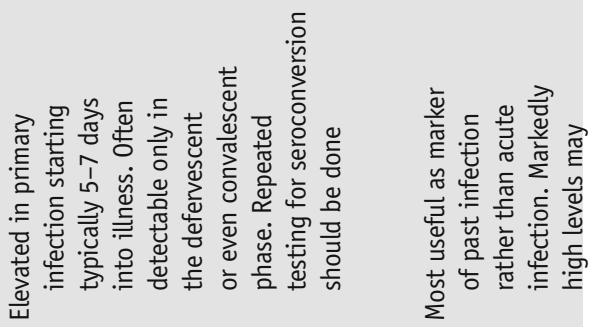

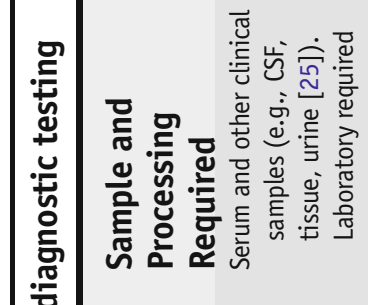

崩

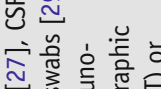

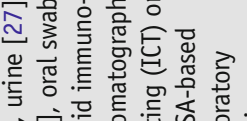

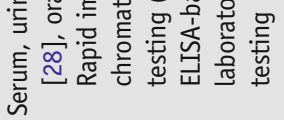

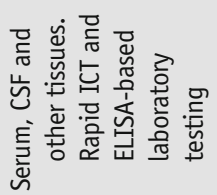

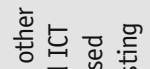

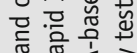

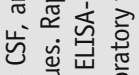

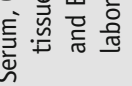

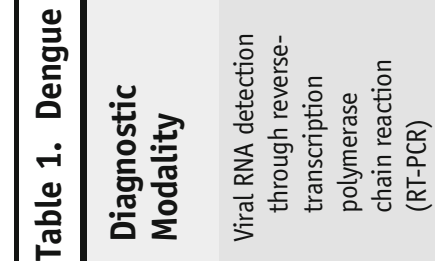

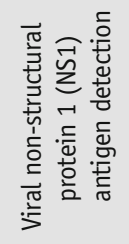

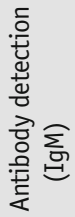

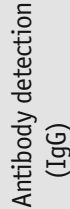




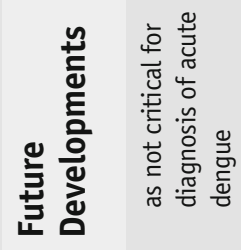
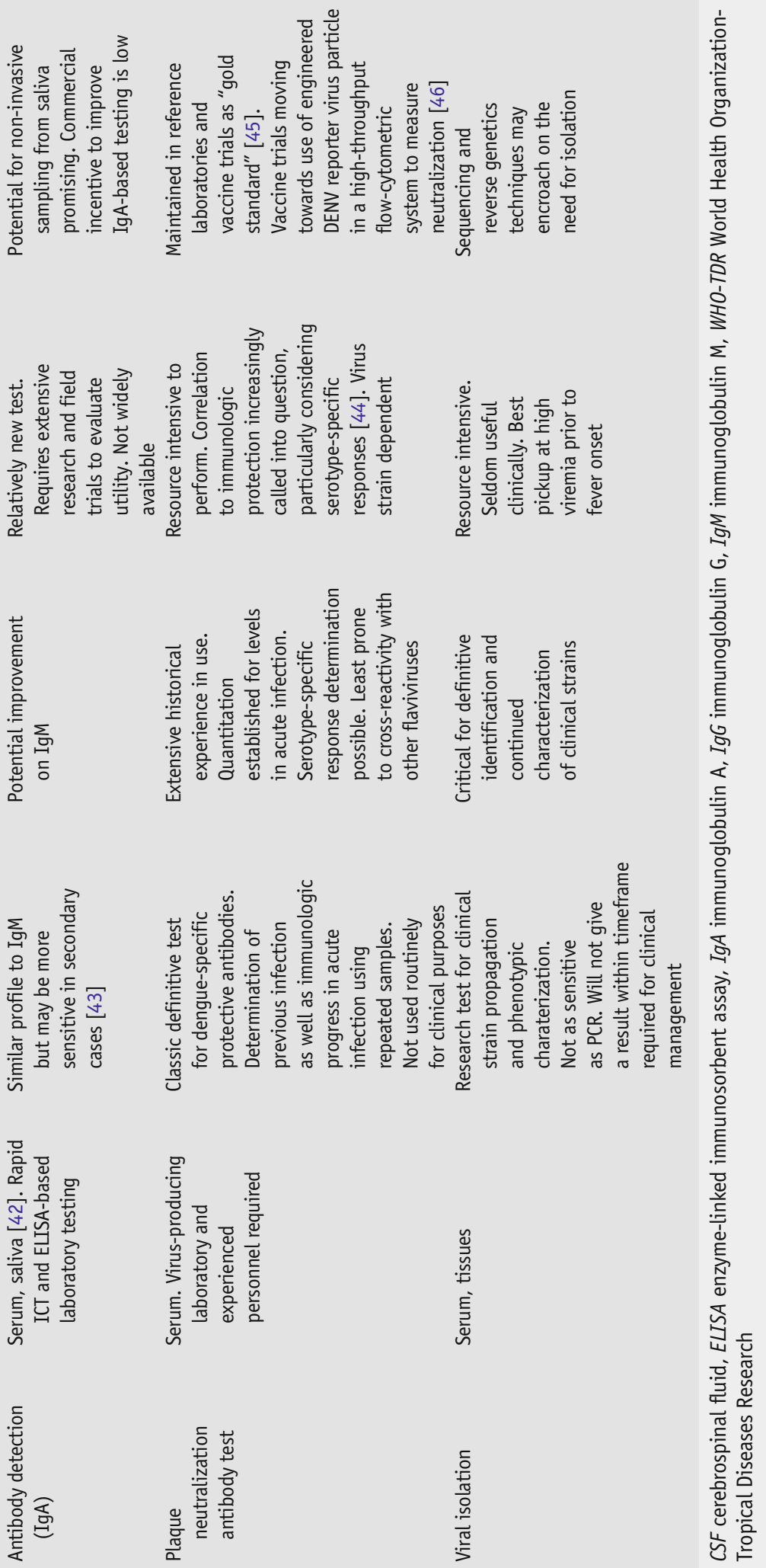
transaminases with an asparatate transaminase:alanine transaminase ratio of $>1$ make dengue the prime candidate. Mild cases that do not reach these values are likely self-limiting or may not benefit from currently available treatment.

There is significant variation between the revised WHO 1997 guidelines [47], regional guidelines $[48 \bullet, 49]$, and national guidelines [50]. Subsequently, recognizing the limitations in the sensitivity of depending solely on a strict adherence to dengue hemorrhagic fever criteria (fever, thrombocytopenia, capillary leak, and hemorrhagic tendency) to determine treatment prioritization [51], WHO proposed new dengue severity classifications and adjusted management algorithms in 2009 [52] and expanded treatment guidelines in 2012 [53••]. While the key principles of timely and judicious fluid repletion are maintained, different criteria have been proposed for triage, hospital admission, and intensive care unit admission, as well as initiation, rates, and cessation of intravenous fluid administration. Criticism of this new guideline centers around two aspects. First, progression to severe dengue is not considered as a single pathophysiologic entity but as a diverse set of manifestations, complicating the streamlining of management, especially by inexperienced staff, and hampering focused pathogenesis research [54]. Second, the broader criteria for clinical diagnosis of dengue and particularly dengue requiring hospitalization is regarded as potentially problematic, taking into account the lack of rapid definitive dengue laboratory diagnosis and lack of inpatient beds especially in outbreak situations [55-58].

\section{Fluid management}

The primary modality for therapeutic intervention in dengue is fluid management. The fundamental principle building on experience in Thailand from the post-war period until now and articulated most clearly in the recent WHO SEARO guidelines [48 ${ }^{\bullet}$ is of dengue as a triphasic syndrome. In the initial febrile phase lasting 3-7 days, serum viremia is present, and increasing capillary permeability leads to a rise in hematocrit. This may be exacerbated by dehydration due to anorexia, nausea, vomiting, diarrhea, and malaise. Together with the development of a serologic response, and associated with defervescence, the critical phase is one where intervention can make the most difference. This is when immunopathologic responses are maximal, reflected in a platelet nadir and rapid rise in hematocrit as fluid shifts out of the intravascular space into the interstitium and third spaces. There is the greatest risk of organ dysfunction exacerbated by edema and microvascular changes during the critical phase, which lasts 1-2 days. The possibility of iatrogenic fluid overload through cumulative fluid administration is also greatest here. Subsequently, during the convalescent phase, blood dyscrasias normalize, inflammatory markers settle, and fluid shifts back into the vasculature. There is a risk of hemodynamic stress if the patient was in fluid overload and the shift of interstitial fluid overwhelms the capacity of the cardiovascular system at this point.

As this dynamic process unfolds, clinical fluid interventions are overlaid on this shifting landscape, making identification of the stage the patient is at the key to good management. Unfortunately, no simple algorithm is able to categorize patient response, given the wide range of variation of ages and fitness represented. Those at higher risk of being unable to cope with these fluid shifts as measured by changes in microvascular permeability (such as children, or 
those genetically predisposed) may be at higher risk of shock [65]. Clinical judgment taking into number of days since fever onset, body temperature, blood pressure, signs of peripheral circulatory status, and signs of fluid overload including radiographic and ultrasonographic studies is required.

Importantly, goal-directed therapy in dengue shock is different from that in septic shock as the physiologic and homeostatic context of the cardiovascular system is distinct in these two syndromes. Even in the fluid management of infection-associated shock, existing guidelines have been called into question by the FEAST trial that showed standard fluid boluses given in hypotension led to increased mortality in such pediatric cases [66]. In addition to goal-directed therapy using catheter-based blood pressure measurement and targets, a more sophisticated approach taking into account measures of tissue perfusion, fluid balance, and capillary leak may be required [67]. These may include such emerging non-invasive technologies such as photoplethysmography which uses changes in pulse oximetry waveforms to indicate changes in cardiovascular status [68], and is being studied in the context of dengue [69].

Dengue patients can be differentiated into three categories for the purposes of fluid management: mild dehydration; significant dehydration at risk of shock or in compensated shock; and decompensated shock due to fluid leakage. Patients may stay in the first category throughout their illness, or move into the second category just before and during the critical phase, or progress further into the third category during the critical phase. The time-dependent progression is important as, for example, aggressive fluid therapy for presumed compensated dengue shock if given early in the course of illness and for a prolonged period of time may lead to fluid overload Table 2 summarizes the key management decision points for clinicians, with selected issues discussed further below.

Treatment of mild dehydration is the mainstay of hospitalized dengue. Oral rehydration using isotonic electrolyte solutions or similar fluids such as coconut water or rice water are recommended in many guidelines. These carry less risk of iatrogenic fluid overload than intravenous administration and have been associated with decreased resource use while maintaining safe outcomes [20]. Antiemetics may be useful to control vomiting. Mild hypokalemia is often encountered, likely associated with vomiting and diarrhea, but is seldom of sufficient magnitude to cause clinical significance and resolves in early convalescence.

Those in the second category may be identified by rapidly rising hematocrit, rapid drop in serum protein or albumin levels, or clinical fluid accumulation such as pulmonary edema and ascites. These are components of the definition of dengue hemorrhagic fever, which requires in addition signs of hemorrhage and thrombocytopenia. Whether the latter are essential to the assignment of atrisk status needing additional fluid administration has been controversial, with the latest WHO SEARO guidelines emphasizing capillary leak criteria over hemorrhagic criteria in determining fluid management [48•]. Determining numerical thresholds for these criteria is challenging given individual physiologic variation. Guidelines currently refer to relative changes in hematocrit over $10 \%$ as a warning sign and changes over $20 \%$ as a clear indication for more aggressive fluid therapy. One model for guiding fluid administration follows an inverted ' $\mathrm{V}$ ' pattern over $48 \mathrm{~h}$, rising from $40 \mathrm{~mL} / \mathrm{h}$ to $200 \mathrm{~mL} / \mathrm{h}$ and falling back to $40 \mathrm{~mL} / \mathrm{h}$ in adults [48•]. Judicious fluid management requires frequent monitoring and sensitivity to clinical status. Isotonic crystalloid is universally recommended in uncomplicated cases except in infants where half-molar 


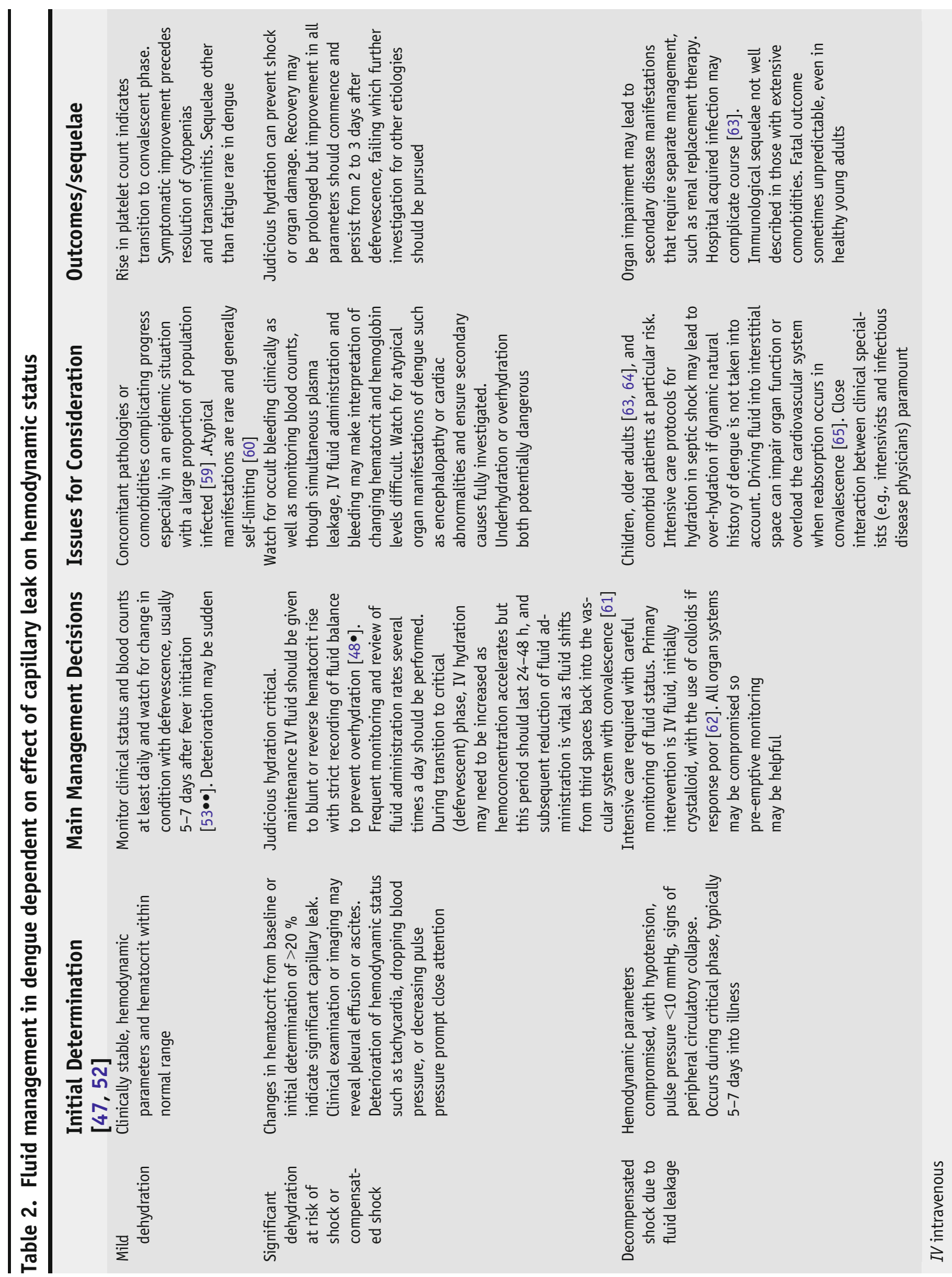


sodium chloride may be used [52]. It should be reiterated that the rates of intravenous fluid administration detailed above are envisioned to be used over a 24- to 48-h period, and subject to clinical monitoring as significant morbidity and mortality can result from fluid overload [70]. The WHO 2009 guidelines also suggest that warning signs are indications for an increased intravenous fluid administration rate over maintenance. There has been vigorous discussion regarding this as the list of warning signs are clinically varied and do not describe a single pathophysiologic syndrome [54], so it may be more appropriate to individualize fluid administration rates rather than group them together under one protocol.

By good fluid management at the transition to the critical phase, the aim is primary prevention of progression to shock. If dengue progresses into shock because of fluid leakage, management should be in an intensive care setting, with the ultimate goal to maintain tissue perfusion. Intensive care protocols such as surviving sepsis bundles will often be applied, but should be tempered by recognition of the different context of fluid shifts in dengue compared with septic shock. Protocols are given in WHO guidelines, including evidence from randomized controlled trials that initial treatment can begin with crystalloid infusions, with hyper-oncotic colloids as a second-line agent where response is not optimal [71, 72]. The ideal is to titrate intravenous fluids along the natural progression of dengue fluid leak, which increases then decreases sharply during the 24- to 48-h critical phase, to blunt the impact on tissue perfusion and hemodynamic homeostasis. The WHO SEARO 2011 guidelines highlight that obese patients should not be given fluids according to actual body weight but according to ideal body weight to avoid fluid overload.

\section{Antiviral and other targeted therapy}

There are as yet no specific antiviral therapies for dengue. Active research is ongoing using in vitro and animal models [73], but few drugs have entered clinical trials. Chloroquine has been shown to be ineffective in reducing viremia [74] and disease duration but may offer limited symptomatic relief [75]. Dengue antiviral research has benefited from the recent intensive effort to discover drugs for the treatment of hepatitis $\mathrm{C}$ virus (HCV), a fellow flavivirus. A number of $\mathrm{HCV}$ drugs that have pre-clinical efficacy against dengue virus have been repurposed and moved on to phase II clinical trials for dengue. Balapiravir was shown to be safe in adults with dengue, but did not lead to changes in the kinetics of viremia or cytokine profiles [76]. Celgosivir, also a repurposed HCV candidate, has similarly shown a lack of success in reducing viral load or fever in patients with dengue [77]. Other candidates are in the drug discovery pipeline, which has been growing with increased global emphasis on neglected tropical diseases [78]. Finally, there is a potential for using dengue-specific antibodies therapeutically by neutralizing dengue virus [79]. The key hurdle to this is ensuring that antibodydependent enhancement of DENV infection does not take place.

\section{Immunomodulatory agents}

A major component of dengue disease is a result of immunopathology, for which the metaphor of a cytokine storm has been used. In the process of 


\section{Vaccine development}

attempting to eliminate dengue virus, changes in physiology occur which, if transient, result in a good outcome after a period of acute morbidity, but in cases where the host physiology is not robust enough to weather the change (e.g., in children or older adults), irreversible damage may result. Though our understanding of the precise nature of the immune response against dengue is still in development, attempts have been made to trial immunomodulatory agents. Intravenous immunoglobulin has been shown to lack efficacy [80, 81]. Recent guidelines have emphasized the lack of evidence for using corticosteroids [82]. A small randomized controlled trial was conducted in Pakistan that showed a limited but statistically significant difference in platelet recovery between treatment and placebo groups using interleukin-11; however, no other clinically significant endpoints were used [83]. Finally, statins exhibit pleiotropic effects on the inflammatory response in humans $[84,85]$ and antiviral effects in mouse models of dengue [86]. A randomized controlled trial is in progress in Vietnam to assess the effect of lovastatin in dengue [87].

A dengue vaccine has been held out as the hope for disease control and eradication since 1929 when the first candidates were evaluated [88, 89]. To date, the Gates Foundation's strategy for dengue is enhanced vaccine research rather than drug discovery. There has been a range of vaccine candidates proposed, using live attenuated virus, chimeric virus, inactivated virus, subunit vaccines, and DNA vaccines [90]. In addition to the usual concerns of safety and immunogenicity, dengue vaccines have been stymied by the prospect of antibody-dependent enhancement, a feature that risks worsening the effect of dengue infection through immunologic memory [91]. This results from the presence of four potentially cross-reactive serotypes, as well as the potential for cross-reactivity with related flaviviruses. All candidates have to be extensively investigated to ensure this theoretical risk is eliminated. There is currently only one candidate in phase III efficacy trials; however, the initial report from a phase IIb pediatric cohort in Thailand indicated poor vaccine efficacy against DENV-2 $[92 \bullet \bullet]$. The results of the full trial in Asia and Latin America are awaited eagerly.

\section{Systems-based management}

\section{Systemic manifestations: pyrexia}

The role of antipyresis in infectious fevers remains inconclusive with the aim being primarily symptomatic relief and the effect on clinical measures of microbiologic clearance, morbidity (e.g., febrile seizures), and mortality not well established $[93,94]$. In dengue, the febrile phase generally lasts 3-7 days with an upper limit of 10 days in unusual cases. A biphasic (or saddleback) pattern has been reported in some cases with a transient defervescence around day 5 and subsequent progression to the critical phase associated with risk of shock and immunolopathologic manifestations. Limited research has been conducted on pharmacologic (paracetamol/acetaminophen) [95] and physical (sponging) methods [96] of antipyresis but both remain recommended in the WHO guidelines for dengue [52]. The utility for analgesia may contribute to the 
near-universal use of paracetamol in dengue. However, the inherent potential for liver toxicity as an adverse effect with paracetamol may be magnified by the tendency of dengue to cause liver inflammation as measured by elevated aminotransferase levels [97-99]. Non-steroidal anti-inflammatory drugs are contraindicated because of the danger of exacerbation of bleeding in the context of depressed platelet levels during acute dengue. For patients receiving longterm antiplatelet therapy with aspirin, clopidogrel, or similar agents, physicians may consider temporarily withholding these drugs until the thrombocytopenia during acute dengue improves, as the risk of thromboembolism during this period is reduced and risk of hemorrhage increased. Finally, corticosteroids have been shown in randomized controlled trials to have no significant impact on outcomes in severe dengue $[82,100-102]$. Though not recommended in guidelines, there remain anecdotal reports of their use in symptomatic relief, though the complex immunopathology of dengue should give physicians reason for careful consideration before use. One important factor in the use of antipyretics for dengue is the critical dependence on the recognition of progression from the febrile phase to the critical (defervescent) phase with the concomitant shifts in fluids that take place during this progression. The amelioration of pyrexia can confuse determination of what phase the patient is in, and subsequently affect decisions on fluid management that depend on the shifting intravascular versus third-space fluid volume of the patient.

Aches and pains are of major clinical significance during dengue, being key symptoms that aid in clinical diagnosis and often are the primary concern of the patient. Bed rest and paracetamol remain the mainstays of management. Less commonly, opiates or even corticosteroids have been used [103]. Rhabdomyolysis, reflected in raised serum creatinine kinase is a recognized complication [104], which in rare cases can lead to acute kidney injury, recently confirmed in one case report with a renal biopsy [105]. In most mild cases, adequate hydration that follows the standard of care for dengue will help recovery. Progression to renal dysfunction though may necessitate hemodialysis. There may also be transient muscle dysfunction associated with muscle weakness and hyporeflexia that does not require treatment and is generally self-limiting [106].

\section{Dermatologic manifestations}

Cutaneous changes in dengue can be polymorphic [107, 108]. The classical dengue rash occurs in two phases: in the early febrile period, generalized flushing occurs, sometimes manifesting as a morbiliform erythematous macular rash, followed in the late febrile and defervescent period by the typical maculopapular rash with "islands of sparing" alongside petechiae and ecchymoses associated with severe thrombocytopenia. In a small number of cases, recovery may be delayed by days to weeks after defervescence, with some residual macular erythema consistent with a delayed-type, T-cell-associated cutaneous reaction. Apart from patient anxiety from the cosmetic effect of the rash that can be alarming in its intensity and spread, the main treatable sequela is pruritis, which occurs in a large proportion of cases. Antihistamines can be used, where the adverse effect of drowsiness may fortuitously aid in supporting bed rest. 
Generally, visual disturbances are rare in dengue, but a number of case series have been reported from epidemics in Singapore [109-112] and India [113, 114]. Symptoms include blurring of vision, subconjunctival hemorrhage, eye flashes, floaters, and retro-orbital pain. Pathologic causes identified include maculopathy, exudates, retinal hemorrhage, retinal detachment, vasculitis, foveitis, choroiditis, and uveitis. These largely occur during the critical (defervescent) phase of dengue and resolve in the convalescent phase, though persistence has been described in a few individuals. Serotype association has been proposed [115] as well as a relationship to autoimmune disease [116]. Full recovery usually occurs in the absence of specific treatment, though systemic and topical corticosteroids have been given with good results in a few cases.

\section{Neurological manifestations}

A recent review of neurologic complications of dengue virus infection used the following categories: encephalopathy, encephalitis, and immune-mediated syndromes in addition to muscular and ophthalmic involvement already covered [117•]. Lack of biopsy findings often precludes definitive diagnosis, as does difficulty in proving dengue virus involvement, especially in regions endemic for cross-reactive flaviviruses where interpretation of serologic testing is not straightforward. Further, when large outbreaks occur that affect significant proportions of residents, Occam's razor may not apply and acute confusional states may have multiple infective or other etiologies. Encephalopathy may be multifactorial, exacerbated by acute liver failure, metabolic derangements, shock, or intracranial hemorrhage. Dengue-associated encephalitis often does not display classical radiographic characteristics of viral encephalitides. These should be treated according to evidence-based guidelines to optimize outcomes. Otherwise, treatment for central nervous system complications of dengue remains supportive. Some anecdotal success has been reported using corticosteroids or intravenous immunoglobulin for immune-mediated complications $[118,119]$ but no randomized controlled trials have taken place.

\section{Hematologic manifestations}

Neutropenia, lymphocytopenia, and thrombocytopenia are all cardinal signs of dengue virus infections that usually resolve within 1-2 weeks. Despite severe neutropenia with an absolute neutrophil count of less than $0.5 \times 10^{9} / \mathrm{L}$ occurring in $12 \%$ of one dengue cohort, it was not associated with poorer outcomes or an increase in secondary infections, and usually resolved within 1 day, thus there may not be a need for routine prophylactic antibiotics [120]. A single case report of the use of filgrastim as rescue therapy for persistent neutropenia in a case with multiple complications and delayed defervescence has been published [121]. The use of granulocyte-colony-stimulating factor has also been described in one Thai pediatric case [122]. Lymphopenia is often the first to resolve, with a rapid increase of reactive lymphocytes being the earliest sign occurring during the defervescent phase. No specific therapy has been described for this.

Thrombocytopenia is of the most concern because of the increased risk of hemorrhage. Minor mucosal bleeding is relatively common, particularly 
transient gingival bleeding or epistaxis, which may be treated with gentle pressure. Tranexamic acid, an anti-fibrinolytic agent, has been suggested in such cases, though it has not yet been formally evaluated in dengue [123, 124].

Excessive vaginal bleeding occurred in $27 \%$ of female adolescents in one Thai study [125] who were treated with premarin, primulute $\mathrm{N}$, or oral contraceptive pills. Oral northethisterone has also been recommended in dengue-associated hypermenorrhea [126]. Gynecologic practice for acute dysfunctional uterine bleeding in general has shifted away from oral hormonal therapy to tranexamic acid and mefanamic acid [127-129]. While the use of the latter in dengue is problematic, tranexamic acid may prove to be useful and awaits further research. Gastrointestinal bleeding in dengue always has the potential to be catastrophic because of its occult nature. In mild cases where no major hemorrhage is suspected, the use of proton pump inhibitors may have a favorable risk-to-benefit ratio. There is no evidence that platelet transfusion as primary prophylaxis in the absence of bleeding independently reduces the risk of bleeding or other severe outcomes [130-132].

Where bleeding is persistent, the administration of platelets may be considered, despite the transience of the effect on platelet levels. However, if blood loss is significant, administration of packed red cells or fresh whole blood is more urgent. Evidence for bleeding may be complicated to assess where bleeding is occult. Watching hemoglobin levels in isolation may give an incomplete picture because of the dynamic fluid shifts in dengue especially during the critical phase. Close watch of the hematocrit, clinical fluid accumulation, fluid balance, and hemodynamic status will provide a more complete picture to determine if the management of bleeding is necessary. Differentiating shock because of hemoconcentration and hemorrhagic shock is critical as the management is fundamentally different. Where bleeding remains uncontrolled, activated recombinant factor VII has been used with success $[133,134]$.

Thrombocytopenia itself has been used as a surrogate for impact on dengue progression in various therapeutic trials without any agents identified as successful in significantly improving platelet recovery in acute infection, as in, for example, high-dose intravenous immunoglobulin [81]. In a few cases, however, unusually persistent thrombocytopenia lasting far beyond the usual convalescent recovery period has been successfully treated with corticosteroids [135, 136].

Finally, there have been increasing reports of dengue-associated hemophagocytic lymphohistiocytosis [137-142] worryingly often associated with death or identified post-mortem. Prompt diagnosis is difficult given the need for biopsy and the complexity of the diagnostic criteria, and treatment may include corticosteroids or intravenous immunoglobulin in milder cases, to the use of cytotoxic and immunomodulatory agents under several trial protocols [143]. sient, not requiring specific therapy [99], there are cases of acute liver failure likely due to a combination of direct viral cytopathic effects, liver ischemia through hemodynamic instability, and immunopathologic sequelae of infection [144]. Apart from supportive measures, a number of studies have 
promoted the use of $\mathrm{N}$-acetylcysteine therapy in dengue-associated acute liver failure [145-147]. There has also been one case report of successful use of the molecular adsorbent recirculating system in dengue hemorrhagic fever [148].

Dengue shock can be associated with respiratory compromise as recognized in the WHO 2009 guidelines [52] often associated with pleural effusion. In the absence of dengue-specific guidelines, use of standard intensive care protocols can be considered. One study recommended nasal continuous positive airway pressure rather than oxygen mask treatment in dengue patients with respiratory failure [149]. Pleural effusion can be the result of over-hydration leading to extravasation and third-space accumulation of fluid. Judicious fluid administration and frequent monitoring is critical to prevent this.

Three major syndromic cardiac manifestations of dengue infection are myocardial impairment, arrythmias, and myocarditis [150•]. Apart from bradycardia, which is common in dengue [151], subtle signs of dysfunction may only be reflected in poorer than expected cardiovascular response to fluid infusion, which is hard to quantify. However, in a Vietnamese case series of 79 pediatric dengue patients uniformly subjected to echocardiography, over half showed signs of myocardial impairment measured by preload-independent indices such as velocities [152]. In an Indian case series of 67 children with severe dengue, $70 \%$ had abnormalities in the Tei index compared with $48 \%$ by ejection fraction and $37 \%$ using the ratio of transmitral Doppler early filling velocity to tissue Doppler early diastolic mitral annular velocity (E/E) while being mostly asymptomatic [153]. As with other organ systems, pathogenesis is likely due to a combination of direct viral cytopathic effects, metabolic derangement, cytokine-mediated immunopathology, interstitial edema, and microvascular changes [150•]. Again, while no dengue-specific protocols have been proposed, the use of standard cardiology regimens has proven successful in case reports [154].

The impact of dengue has the potential for severe morbidity in young and healthy individuals, especially in situations of massive outbreaks, as have been happening, for example, in Lahore, Pakistan in 2011, with 500,000 notified cases in a city of 5 million, and a dengue IgG seropositivity rate of $67.9 \%$ the following year in a city not previously endemic for dengue [155]. Physicians unfamiliar with dengue may at short notice have to deal with critically ill patients either in an outbreak or as a result of travel-related dengue infection [156]. Management experience in severe dengue has largely occurred in the context of pediatric cases. Because of demographic transitions, climaticoecologic change, and epidemiologic trends, adults are increasingly affected and thus we may have to focus on ensuring guidelines remain relevant or updated [157]. Increasingly, older adults are seen to be at risk from denguerelated mortality $[63,158]$. A broad range of virologic, immunologic, clinical, and implementation science research will be required to combat this emerging pandemic. 


\section{Acknowledgments}

Managing adult dengue cases at the Communicable Disease Centre in Tan Tock Seng Hospital, Singapore has shaped my clinical experience, and I am most appreciative of my mentors Prof. Yee-Sin Leo and Dr. David Lye. I am grateful for collaborations with local and regional dengue experts facilitated through my appointment as clinical lead of the STOP Dengue Translational Clinical Research Programme, funded by the National Research Foundation through the National Medical Research Council, Singapore (Grant NMRC/TCR/005/2008).

\section{Compliance with Ethics Guidelines}

\section{Conflict of Interest}

Victor C. Gan declares no conflicts of interest.

\section{Human and Animal Rights and Informed Consent}

This article does not contain any studies with human or animal subjects performed by the author.

Open Access This article is distributed under the terms of the Creative Commons Attribution License which permits any use, distribution, and reproduction in any medium, provided the original author(s) and the source are credited.

\section{References and Recommended Reading}

Papers of particular interest, published recently, have been highlighted as:

- Of importance

$\bullet \quad$ Of major importance

1. Normile D. Tropical medicine: surprising new dengue virus throws a spanner in disease control efforts.

Science. 2013;342(6157):415.

2. Bhatt S, Gething PW, Brady OJ, Messina JP, Farlow AW, Moyes CL, et al. The global distribution and burden of dengue. Nature. 2013;496(7446):504-7.

3. Simmons CP, Farrar JJ, van Nguyen VC, Wills B. Dengue. N Engl J Med. 2012;366(15):1423-32.

This is the most recent authoritative overview of dengue for the non-specialist, from the Oxford University Clinical Research Unit in Vietnam.

4. Carey DE. Chikungunya and dengue: a case of mistaken identity? J Hist Med Allied Sci. 1971;26(3):243-62.

5. Brathwaite Dick O, San Martín JL, Montoya RH, del Diego J, Zambrano B, Dayan GH. The history of dengue outbreaks in the Americas. Am J Trop Med Hyg. 2012;87(4):584-93.

6. Rush B. An account of the bilious remitting yellow fever as it appeared in Philadelphia in 1780: medical inquiries and observations. Philadelphia: Prichard and Hall; 1789 . p. 89-100.

7. Bassett-Smith PW. Dengue fever in Bombay. Indian Med Gaz. 1897;32:230.

8. Christie J. On epidemics of dengue fever: their diffusion and etiology. Glasg Med J. 1881;16:161-76.
9. Dickson SH. Account of the dengue, as it appeared in Charleston, SC during the summer of 1828. Am J Med Sci. 1828;5:3-14.

10. Boschberg P. The trade, forgery and medicinal use of porcupine bezoars in the early modern period (c.15001750). In: Pinto CA, editor. Oriente. Lisbon: Fundação Oriente/ Orient Foundation; 2006. p. 60-78.

11. Barroso MDS. Bezoar stones, magic, science and art. Geol Soc Lond Spec Publ. 2013;375(1):193-207.

12. Wong LP, AbuBakar S. Health beliefs and practices related to dengue fever: a focus group study. PLoS Negl Trop Dis. 2013;7(7):e2310.

13. Ahmad N, Fazal H, Ayaz M, Abbasi BH, Mohammad I, Fazal L. Dengue fever treatment with Carica papaya leaves extracts. Asian Pac J Trop Biomed. 2011;1(4):330-3.

14. Hettige S. Salutary effects of Carica papaya leaf extract in dengue fever patients: a pilot study. Sri Lankan Fam Physician. 2008;29:17-9.

15. Sathasivam K, Ramanathan S, Mansor SM, Haris MRMH, Wernsdorfer WH. Thrombocyte counts in mice after the administration of papaya leaf suspension. Wien Klin Wochenschr. 2009; 121 Suppl 3:19-22.

16. Subenthiran S, Choon TC, Cheong KC, Thayan R, Teck MB, Muniandy PK, et al. Carica papaya leaves juice 
significantly accelerates the rate of increase in platelet count among patients with dengue fever and dengue hemorrhagic fever. Evid Based Complement Alternat Med. 2013. doi:10.1155/2013/616737.

17. Halstead SB, Yamarat C. Recent epidemics of hemorrhagic fever in Thailand: observations related to pathogenesis of a "new" dengue disease. Am J Public Health Nations Health. 1965;55:1386-95.

18. Technical Advisory Committee on Dengue hemorrhagic Fever for the South East Asian and Western Pacific Regions. Technical guides for diagnosis, treatment, surveillance, prevention and control of dengue hemorrhagic fever. Geneva: World Health Organization; 1975.

19. Kalayanarooj S. Standardized clinical management: evidence of reduction of dengue hemorrhagic fever case-fatality rate in Thailand. Dengue Bull. 1999;23:10-7.

20. Rocha C, Silva S, Gordon A, Hammond SN, Elizondo D, Balmaseda A, et al. Improvement in hospital indicators after changes in dengue case management in Nicaragua. Am J Trop Med Hyg. 2009;81(2):287-92.

21. Lee LK, Earnest A, Carrasco LR, Thein TL, Gan VC, Lee VJ, et al. Safety and cost savings of reducing adult dengue hospitalization in a tertiary care hospital in Singapore. Trans R Soc Trop Med Hyg. 2013;107(1):37-42.

22. Kalayanarooj S, Vaughn DW, Nimmannitya S, Green S, Suntayakorn S, Kunentrasai N, et al. Early clinical and laboratory indicators of acute dengue illness. J Infect Dis. 1997; 176(2):313-21.

23. Gregory CJ, Santiago LM, Argüello DF, Hunsperger E, Tomashek KM. Clinical and laboratory features that differentiate dengue from other febrile illnesses in an endemic area: Puerto Rico, 2007-2008. Am J Trop Med Hyg. 2010;82(5):922-9.

24. Low JGH, Ong A, Tan LK, Chaterji S, Chow A, Lim WY, et al. The early clinical features of dengue in adults: challenges for early clinical diagnosis. PLoS Negl Trop Dis. 2011;5(5):e1191.

25. Hirayama T, Mizuno Y, Takeshita N, Kotaki A, Tajima $\mathrm{S}, \mathrm{Omatsu} \mathrm{T}$, et al. Detection of dengue virus genome in urine by real-time reverse transcriptase PCR: a laboratory diagnostic method useful after disappearance of the genome in serum. J Clin Microbiol. 2012;50(6):2047-52.

26. Domingo C, Niedrig M, Teichmann A, Kaiser M, Rumer L, Jarman RG, et al. 2nd international external quality control assessment for the molecular diagnosis of dengue infections. PLoS Negl Trop Dis.

2010;4(10):e833.

27. Chuansumrit A, Chaiyaratana W, Tangnararatchakit $K$, Yoksan S, Flamand M, Sakuntabhai A. Dengue nonstructural protein 1 antigen in the urine as a rapid and convenient diagnostic test during the febrile stage in patients with dengue infection. Diagn Microbiol Infect Dis. 2011;71(4):467-9.

28. Araújo FMC, Brilhante RSN, Cavalcanti LPG, Rocha MFG, Cordeiro RA, Perdigão ACB, et al. Detection of the dengue non-structural 1 antigen in cerebral spinal fluid samples using a commercially available enzymelinked immunosorbent assay. J Virol Methods. 2011;177:128-31.

29. Anders KL, Nguyet NM, Quyen NTH, Ngoc TV, Tram TV, Gan TT, et al. An evaluation of dried blood spots and oral swabs as alternative specimens for the diagnosis of dengue and screening for past dengue virus exposure. Am J Trop Med Hyg. 2012;87(1):165-70.

30. Tricou V, Minh NN, Farrar J, Tran HT, Simmons CP. Kinetics of viremia and NS1 antigenemia are shaped by immune status and virus serotype in adults with dengue. PLoS Negl Trop Dis. 2011;5(9):e1309.

31. Pok K-Y, Lai Y-L, Sng J, Ng L-C. Evaluation of nonstructural 1 antigen assays for the diagnosis and surveillance of dengue in Singapore. Vector Borne Zoonotic Dis. 2010;10(10):1009-16.

32. Gan VC, Tan L-K, Lye DC, Pok K-Y, Mok S-Q, Chua RC$\mathrm{R}$, et al. Diagnosing dengue at the point-of-care: utility of a rapid combined diagnostic kit in Singapore. PLoS One. 2014;9(3):e90037.

33. Andries A-C, Duong V, Ngan C, Ong S, Huy R, Sroin $\mathrm{KK}$, et al. Field evaluation and impact on clinical management of a rapid diagnostic kit that detects dengue NS1, IgM and IgG. PLoS Negl Trop Dis. 2012;6(12):e1993.

34. Fry SR, Meyer M, Semple MG, Simmons CP, Sekaran SD, Huang JX, et al. The diagnostic sensitivity of dengue rapid test assays is significantly enhanced by using a combined antigen and antibody testing approach. PLoS Negl Trop Dis. 2011;5(6):e1199.

35. Blacksell SD, Doust JA, Newton PN, Peacock SJ, Day NPJ, Dondorp AM. A systematic review and metaanalysis of the diagnostic accuracy of rapid immunochromatographic assays for the detection of dengue virus IgM antibodies during acute infection. Trans R Soc Trop Med Hyg. 2006;100(8):775-84.

36. Da Costa VG, Marques-Silva AC, Moreli ML. A metaanalysis of the diagnostic accuracy of two commercial NS1 antigen ELISA tests for early dengue virus detection. PLoS One. 2014;9(4):e94655.

37. Sea VRF, Cruz ACR, Gurgel RQ, Nunes BTD, Silva EVP, Dolabella SS, et al. Underreporting of Dengue-4 in Brazil due to low sensitivity of the NS1 Ag test in routine control programs. PLoS One. 2013;8(5):e64056.

38. Puttikhunt C, Prommool T, U-thainual N, Ongajchaowlerd P, Yoosook K, Tawilert C, et al. The development of a novel serotyping-NS1-ELISA to identify serotypes of dengue virus. J Clin Virol Off Publ Pan Am Soc Clin Virol. 2011;50(4):314-9.

39. Ding $X, H u$ D, Chen $Y$, Di B, Jin J, Pan Y, et al. Full serotype- and group-specific NS1 capture enzymelinked immunosorbent assay for rapid differential diagnosis of dengue virus infection. Clin Vaccine Immunol CVI. 2011;18(3):430-4.

40. World Health Organization. Evaluation of commercially available anti-dengue virus immunoglobulin $\mathrm{M}$ tests. Geneva: World Health Organization; 2009. 
41. Hunsperger EA, Yoksan S, Buchy P, Nguyen VC, Sekaran SD, Enria DA, et al. Evaluation of commercially available anti-dengue virus immunoglobulin $\mathrm{M}$ tests. Emerg Infect Dis. 2009;15(3):436-40.

42. Yap G, Sil BK, Ng L-C. Use of saliva for early dengue diagnosis. PLoS Negl Trop Dis. 2011;5(5):e1046.

43. Tan YY, Sekaran SD, Wang SM, Ahmed F, Hossain A, Sil BK. Development of ASSURE dengue IgA rapid test for the detection of anti-dengue IgA from dengue infected patients. J Glob Infect Dis. 2011;3(3):233-40.

44. Sirivichayakul C, Sabchareon A, Limkittikul K, Yoksan $S$. Plaque reduction neutralization antibody test does not accurately predict protection against dengue infection in Ratchaburi cohort. Thail Virol J. 2014;11(1):48.

45. Roehrig JT, Hombach J, Barrett ADT. Guidelines for plaque-reduction neutralization testing of human antibodies to dengue viruses. Viral Immunol. 2008;21(2):123-32.

46. Mattia K, Puffer BA, Williams KL, Gonzalez R, Murray $\mathrm{M}$, Sluzas E, et al. Dengue reporter virus particles for measuring neutralizing antibodies against each of the four dengue serotypes. PLoS ONE. 2011;6(11):e27252.

47. World Health Organization. Dengue hemorrhagic fever: diagnosis, treatment, prevention and control. 2nd ed. Geneva: World Health Organization; 1997.

48. World Health Organization, Regional Office for South East Asia. Comprehensive guidelines for prevention and control of dengue and dengue hemorrhagic fever: revised and expanded edition. New Delhi, India: World Health Organization; 2011.

This updated WHO SEARO guideline contains the latest revision of the dengue hemorrhagic fever/dengue shock syndrome classification along with protocols developed and practised in Bangkok.

49. Pan American Sanitary Bureau, editor. Dengue and dengue hemorrhagic fever in the Americas: guidelines for prevention and control. Washington, D.C: Pan American Health Organization, Pan American Sanitary Bureau, Regional Office of the World Health Organization; 1994

50. Santamaria R, Martinez E, Kratochwill S, Soria C, Tan LH, Nuñez A, et al. Comparison and critical appraisal of dengue clinical guidelines and their use in Asia and Latin America. Int Health. 2009;1(2):133-40.

51. Balmaseda A, Hammond SN, Perez MA, Cuadra R, Solano S, Rocha J, et al. Assessment of the World Health Organization scheme for classification of dengue severity in Nicaragua. Am J Trop Med Hyg. 2005;73(6):1059.

52. World Health Organization. Dengue: guidelines for diagnosis, treatment, prevention and control. Newth ed. Geneva: World Health Organization; 2009.

53.• WHO Department of Control of Neglected Tropical Diseases (WHO/NTD), Special Programme for Research and Training in Tropical Diseases (WHO/TDR). Handbook for clinical management of dengue. Geneva: World Health Organization; 2012.

The most detailed international dengue management guidelines by WHO being the current standard of care.
54. Halstead SB. Dengue: the syndromic basis to pathogenesis research. Inutility of the 2009 WHO case definition. Am J Trop Med Hyg. 2013;88(2):212-5.

55. Srikiatkhachorn A, Rothman AL, Gibbons RV, Sittisombut N, Malasit P, Ennis FA, et al. Dengue: how best to classify it. Clin Infect Dis Off Publ Infect Dis Soc Am. 2011;53(6):563-7.

56. Kalayanarooj S. Dengue classification: current WHO vs. the newly suggested classification for better clinical application? J Med Assoc Thail Chotmaihet Thangphaet. 2011;94 Suppl 3:S74-84.

57. Gan VC, Lye DC, Thein TL, Dimatatac F, Tan AS, Leo Y$\mathrm{S}$. Implications of discordance in world health organization 1997 and 2009 dengue classifications in adult dengue. PLoS One. 2013;8(4):e60946.

58. Leo Y-S, Gan VC, Ng E-L, Hao Y, Ng L-C, Pok K-Y, et al. Utility of warning signs in guiding admission and predicting severe disease in adult dengue. BMC Infect Dis. 2013; 13:498.

59. Pang J, Salim A, Lee VJ, Hibberd ML, Chia KS, Leo YS, et al. Diabetes with hypertension as risk factors for adult dengue hemorrhagic fever in a predominantly dengue serotype 2 epidemic: a case control study. PLoS Negl Trop Dis. 2012;6(5):e1641.

60. Gulati S, Maheshwari A. Atypical manifestations of dengue. Trop Med Int Health TM IH. 2007;12(9):1087-95.

61. Premaratna R, Ragupathy A, Miththinda JKND, de Silva HJ. Timing, predictors, and progress of third space fluid accumulation during preliminary phase fluid resuscitation in adult patients with dengue. Int J Infect Dis Off Publ Int Soc Infect Dis. 2013;17(7):e505-9.

62. Lam PK, Tam DTH, Diet TV, Tam CT, Tien NTH, Kieu NTT, et al. Clinical characteristics of dengue shock syndrome in Vietnamese children: a 10-year prospective study in a single hospital. Clin Infect Dis. 2013;57(11):1577-86.

63. Rowe EK, Leo Y-S, Wong JGX, Thein T-L, Gan VC, Lee $\mathrm{LK}$, et al. Challenges in dengue fever in the elderly: atypical presentation and risk of severe dengue and hospital-acquired infection. PLoS Negl Trop Dis. 2014;8(4):e2886.

64. Lee C-C, Hsu H-C, Chang C-M, Hong M-Y, Ko W-C. Atypical presentations of dengue disease in the elderly visiting the ED. Am J Emerg Med. 2013;31(5):783-7.

65. Bethell DB, Gamble J, Loc PP, Dung NM, Chau TTH, Loan HT, et al. Noninvasive measurement of microvascular leakage in patients with dengue hemorrhagic fever. Clin Infect Dis. 2001;32(2):243-53.

66. Maitland K, Kiguli S, Opoka RO, Engoru C, OlupotOlupot P, Akech SO, et al. Mortality after fluid bolus in African children with severe infection. N Engl J Med. 2011;364(26):2483-95.

67. Cordemans C, Inneke D l, Van Regenmortel N, Schoonheydt K, Dits H, Huber W, et al. Fluid management in critically ill patients: the role of extravascular lung water, abdominal hypertension, capillary leak, and fluid balance. Ann Intensive Care. 2012;2 Suppl $1: S 1$. 
68. Sahni R. Noninvasive monitoring by photoplethysmography. Clin Perinatol. 2012;39(3):573-83.

69. Moulton S, Mulligan J, Srikiatkhachorn A, Kalayanarooj S, Grudic G, Green S, et al. Noninvasive method for fluid resuscitation monitoring in dengue hemorrhagic fever: a preliminary report. The 3rd International Conference on Dengue and Dengue hemorrhagic Fever; 2013 Oct; Bangkok, Thailand. http:// www.dengue2013bangkok.com/abstract_submission/ online/380. Accessed Accessed 14 March 2014

70. Cook A, Leo Y, Gan V, Dimatatac F, Tan A, Lye D. Potential adverse outcomes of maintenance intravenous fluid in adult dengue without plasma leakage: an observational cohort study. Int J Infect Dis.

2012;16:e36.

71. Dung NM, Day NP, Tam DT, Loan HT, Chau HT, Minh $\mathrm{LN}$, et al. Fluid replacement in dengue shock syndrome: a randomized, double-blind comparison of four intravenous-fluid regimens. Clin Infect Dis Off Publ Infect Dis Soc Am. 1999;29(4):787-94.

72. Wills BA, Dung NM, Loan HT, Tam DTH, Thuy TTN, Minh LTT, et al. Comparison of three fluid solutions for resuscitation in dengue shock syndrome. $\mathrm{N}$ Engl J Med. 2005;353(9):877-89.

73. Lim SP, Wang Q-Y, Noble CG, Chen Y-L, Dong H, Zou $\mathrm{B}$, et al. Ten years of dengue drug discovery: progress and prospects. Antivir Res. 2013;100(2):500-19.

74. Tricou V, Minh NN, Van TP, Lee SJ, Farrar J, Wills B, et al. A randomized controlled trial of chloroquine for the treatment of dengue in Vietnamese adults. PLoS Negl Trop Dis. 2010;4(8):e785.

75. Borges MC, Castro LA, da Fonseca BAL, Borges MC, Castro LA, da Fonseca BAL. Chloroquine use improves dengue-related symptoms. Mem Inst Oswaldo Cruz. 2013;108(5):596-9.

76. Nguyen NM, Tran CNB, Phung LK, Duong KTH, Huynh HA, Farrar J, et al. A randomized, double-blind placebo controlled trial of balapiravir, a polymerase inhibitor, in adult dengue patients. J Infect Dis. 2013;207(9):1442-50.

77. Low JG, Sung C, Wijaya L, Wei Y, Rathore APS, Watanabe S, et al. Efficacy and safety of celgosivir in patients with dengue fever (CELADEN): a phase $1 \mathrm{~b}$, randomised, double-blind, placebo-controlled, proofof-concept trial. Lancet Infect Dis. 2014 May 27. doi:10.1016/S1473-3099(14)70730-3

78. Middleton J. Wellcome Trust and KU Leuven announce collaboration with Janssen for development of dengue antiviral drugs [Internet]. Wellcome Trust; 2013 [cited 2014 Apr 21]. Available from: http:// www.wellcome.ac.uk/News/Media-office/Press-releases/2013/WTP053792.htm

79. Chan KR, Ong EZ, Ooi EE. Therapeutic antibodies as a treatment option for dengue fever. Expert Rev Anti Infect Ther. 2013;11(11):1147-57.

80. Rajapakse S. Intravenous immunoglobulins in the treatment of dengue illness. Trans R Soc Trop Med Hyg. 2009;103(9):867-70.
81. Dimaano EM, Saito M, Honda S, Miranda EA, Alonzo MTG, Valerio MD, et al. Lack of efficacy of high-dose intravenous immunoglobulin treatment of severe thrombocytopenia in patients with secondary dengue virus infection. Am J Trop Med Hyg. 2007;77(6):1135-8.

82. Panpanich R, Sornchai P, Kanjanaratanakorn K. Corticosteroids for treating dengue shock syndrome. Cochrane Database Syst Rev. 2006;3, CD003488.

83. Suliman MI, Qayum I, Saeed F. Randomized clinical trial of human interleukin-11 in dengue feverassociated thrombocytopenia. J Coll Physician Surg Pak. 2014;24(3):164-8.

84. Steiner S, Speidl WS, Pleiner J, Seidinger D, Zorn G, Kaun C, et al. Simvastatin blunts endotoxin-induced tissue factor in vivo. Circulation. 2005;111(14):1841-6.

85. Falagas ME, Makris GC, Matthaiou DK, Rafailidis PI. Statins for infection and sepsis: a systematic review of the clinical evidence. J Antimicrob Chemother. 2008;61(4):774-85.

86. Martinez-Gutierrez M, Correa-Londoño LA, Castellanos JE, Gallego-Gómez JC, Osorio JE. Lovastatin delays infection and increases survival rates in AG129 mice infected with dengue virus serotype 2 . PLoS ONE. 2014;9(2):e87412.

87. Whitehorn J, Chau NVV, Truong NT, Tai LTH, Hao NV, Hien TT, et al. Lovastatin for adult patients with dengue: protocol for a randomised controlled trial. Trials. 2012;13(1):203.

88. Blac G, Caminopetros J. Recherches experimentales sur la dengue. Ann Inst Pasteur Paris. 1930;44(4):367-436.

89. Simmons M, St John J, Reynolds F. Experimental studies of dengue. Philipp J Sci. 1931;44:1-252.

90. Thisyakorn U, Thisyakorn C. Latest developments and future directions in dengue vaccines. Ther Adv Vaccines. 2014;2(1):3-9.

91. Whitehead SS, Blaney JE, Durbin AP, Murphy BR. Prospects for a dengue virus vaccine. Nat Rev Microbiol. 2007;5(7):518-28.

92.• Sabchareon A, Wallace D, Sirivichayakul C, Limkittikul $\mathrm{K}$, Chanthavanich P, Suvannadabba S, et al. Protective efficacy of the recombinant, live-attenuated, CYD tetravalent dengue vaccine in Thai schoolchildren: a randomised, controlled phase $2 \mathrm{~b}$ trial. Lancet. 2012;380(9853):1559-67.

The first efficacy results from the most promising dengue vaccine candidate were unexpectedly poor but this and related publications are critical to future research and planning.

93. Aronoff DM, Neilson EG. Antipyretics: mechanisms of action and clinical use in fever suppression. Am J Med. 2001;111(4):304-15.

94. Sullivan JE, Farrar HC. Fever and antipyretic use in children. Pediatrics. 2011;127(3):580-7.

95. Meremikwu M, Oyo-Ita A. Paracetamol for treating fever in children. Cochrane Database Syst Rev. 2002;2, CD003676.

96. Meremikwu M, Oyo-Ita A. Physical methods for treating fever in children. Cochrane Database Syst Rev. 2003;2, CD004264. 
97. Ling LM, Wilder-Smith A, Leo YS. Fulminant hepatitis in dengue hemorrhagic fever. J Clin Virol Off Publ Pan Am Soc Clin Virol. 2007;38(3):265-8.

98. Gan CS, Chong SY, Lum LCS, Lee WS. Regular paracetamol in severe dengue: a lethal combination? Singap Med J. 2013;54(2):e35-7.

99. Lee LK, Gan VC, Lee VJ, Tan AS, Leo YS, Lye DC. Clinical relevance and discriminatory value of elevated liver aminotransferase levels for dengue severity. PLoS Negl Trop Dis. 2012;6(6):e1676.

100. Nguyen THT, Nguyen THQ, Vu TT, Farrar J, Hoang TL, Dong THT, et al. Corticosteroids for dengue: why don't they work? PLoS Negl Trop Dis. 2013;7(12):e2592.

101. Rajapakse S. Corticosteroids in the treatment of dengue illness. Trans R Soc Trop Med Hyg. 2009;103(2):122-6.

102. Tam DTH, Ngoc TV, Tien NTH, Kieu NTT, Thuy TTT, Thanh LTC, et al. Effects of short-course oral corticosteroid therapy in early dengue infection in Vietnamese patients: a randomized, placebo-controlled trial. Clin Infect Dis. 2012;55(9):1216-24.

103. Finsterer J, Kongchan K. Severe, persisting, steroidresponsive dengue myositis. J Clin Virol. 2006;35(4):426-8.

104. Davis JS, Bourke P. Rhabdomyolysis associated with dengue virus infection. Clin Infect Dis Off Publ Infect Dis Soc Am. 2004;38(10):e109-11.

105. Repizo LP, Malheiros DM, Yu L, Barros RT, Burdmann EA. Biopsy proven acute tubular necrosis due to rhabdomyolysis in a dengue fever patient: a case report and review of literature. Rev Inst Med Trop Sao Paulo. 2014;56(1):85-8.

106. Misra UK, Kalita J, Maurya PK, Kumar P, Shankar SK, Mahadevan A. Dengue-associated transient muscle dysfunction: clinical, electromyography and histopathological changes. Infection. 2012;40(2):125-30.

107. Desruelles F, Lamaury I, Roudier M, Goursaud R, Mahé A, Castanet J, et al. Manifestations cutaneomuqueuses de la dengue. Ann Dermatol Venereol. 1997; 124(3):237-41.

108. Thomas EA, John M, Bhatia A. Cutaneous manifestations of dengue viral infection in Punjab (north India). Int J Dermatol. 2007;46(7):715-9.

109. Chan DPL, Teoh SCB, Tan CSH, Nah GKM, Rajagopalan R, Prabhakaragupta MK, et al. Ophthalmic complications of dengue. Emerg Infect Dis. 2006;12(2):285-9.

110. Chlebicki MP, Ang B, Barkham T, Laude A. Retinal hemorrhages in 4 patients with dengue fever. Emerg Infect Dis. 2005;11(5):770-2.

111. Seet RCS, Quek AML, Lim ECH. Symptoms and risk factors of ocular complications following dengue infection. J Clin Virol Off Publ Pan Am Soc Clin Virol. 2007;38(2):101-5.

112. Bacsal K, Chee S, Cheng C, Flores J. Dengueassociated maculopathy. Arch Ophthalmol. 2007;125(4):501-10.
113. Gupta A, Srinivasan R, Setia S, Soundravally R, Pandian DG. Uveitis following dengue fever. Eye. 2008;23(4):873-6.

114. Kapoor HK, Bhai S, John M, Xavier J. Ocular manifestations of dengue fever in an East Indian epidemic. Can J Ophthalmol. 2006;41(6):741-6.

115. Chee E, Sims JL, Jap A, Tan BH, Oh H, Chee S-P. Comparison of prevalence of dengue maculopathy during two epidemics with differing predominant serotypes. Am J Ophthalmol. 2009;148(6):910-3.

116. Chang PEJ, Cheng CL, Asok K, Fong KY, Chee SP, Tan CK. Visual disturbances in dengue fever: an answer at last? Singap Med J. 2007;48(3):e71-3.

117. Carod-Artal FJ, Wichmann O, Farrar J, Gascón J. Neurological complications of dengue virus infection. Lancet Neurol. 2013;12(9):906-19.

A comprehensive overview of nervous system manifestations of dengue virus infection.

118. Gupta M, Nayak R, Khwaja GA, Chowdhury D. Acute disseminated encephalomyelitis associated with dengue infection: a case report with literature review. J Neurol Sci. 2013;335(1-2):216-8.

119. Sharma CM, Kumawat BL, Ralot T, Tripathi G, Dixit S. Guillain-Barre syndrome occurring during dengue fever. J Indian Med Assoc. 2011 Sep;109(9):675-82.

120. Thein T-L, Lye DC, Leo Y-S, Wong JGX, Hao Y, WilderSmith A. Severe neutropenia in dengue patients: prevalence and significance. Am J Trop Med Hyg. 2014;90(6):984-7.

121. Deepak D, Garg R, Pawar M, Banerjee N, Solanki R, Maurya I. Filgrastim as a rescue therapy for persistent neutropenia in a case of dengue hemorrhagic fever with acute respiratory distress syndrome and myocarditis. Case Rep Anesthesiol. 2011. doi:10.1155/2011/896783

122. Insiripong S. Agranulocytosis in dengue hemorrhagic fever: a neglected condition. J Med Assoc Thail Chotmaihet Thangphaet. 2010;93(4):502-4.

123. Chuansumrit A, Tangnararatchakit K. Pathophysiology and management of dengue hemorrhagic fever. Transfus Altern Transfus Med. 2006;8(s1):3-11.

124. Gunawardane N, Wijewickrama A, Dissanayake U, Sellahewa K, Tissera H. Guidelines on management of dengue fever and dengue hemorrhagic fever in adults. Colombo: Ministry of Health, Sri Lanka; 2010.

125. Tangnararatchakit K, Chuansumrit A, Chaiyaratana W, Lertwongrath S, Gajaseeni N, Udomchaisakul R, et al. Excessive menstrual bleeding in adolescents with dengue infection. Pediatr Infect Dis J. 2010;29(1):92-3.

126. Lim PL. Advice on dengue fever for an American student going to live two years in Asia [Internet]. International Society for Travel Medicine; 2013. Available from: http://www.istm.org/Documents/ Members/MemberResources/publications/handouts/ expert/Case2013-1.pdf. Accessed 14 March 2014.

127. Preston JT, Cameron IT, Adams EJ, Smith SK. Comparative study of tranexamic acid and norethisterone in the treatment of ovulatory menorrhagia. Br J Obstet Gynaecol. 1995;102(5):401-6. 
128. Roy SN, Bhattacharya S. Benefits and risks of pharmacological agents used for the treatment of menorrhagia. Drug Saf Int J Med Toxicol Drug Exp. 2004;27(2):75-90.

129. Oehler MK, Rees MCP. Menorrhagia: an update. Acta Obstet Gynecol Scand. 2003;82(5):405-22.

130. Lum LCS, Abdel-Latif ME-A, Goh AYT, Chan PWK, Lam SK. Preventive transfusion in dengue shock syndrome: is it necessary? J Pediatr. 2003;143(5):682-4.

131. Lye DC, Lee VJ, Sun Y, Leo YS. Lack of efficacy of prophylactic platelet transfusion for severe thrombocytopenia in adults with acute uncomplicated dengue infection. Clin Infect Dis. 2009;48(9):1262-5.

132. Kurukularatne C, Dimatatac F, Teo DL, Lye DC, Leo YS. When less is more: can we abandon prophylactic platelet transfusion in Dengue fever? Ann Acad Med Singap. 2011;40(12):539-45.

133. Chuansumrit A, Teeraratkul S, Wanichkul S, Treepongkaruna S, Sirachainan N, Pakakasama S, et al. Recombinant-activated factor VII for control and prevention of hemorrhage in nonhemophilic pediatric patients. Blood Coagul Fibrinolysis Int J Haemost Thromb. 2010;21(4):354-62.

134. Bhat S, Yadav SP, Anjan M, Dinand V, Sachdeva A. Recombinant activated Factor VII usage in life threatening hemorrhage: a pediatric experience. Indian J Pediatr. 2011;78(8):961-8.

135. Leong KW, Srinivas P. Corticosteroid-responsive prolonged thrombocytopenia following dengue hemorrhagic fever. Med J Malays. 1993;48(3):369-72.

136. Verma SP, Hamide A, Wadhwa J, Sivamani K. Corticosteroid responsive prolonged thrombocytopenia in a case of dengue fever. BMJ Case Rep. 2013;2013:200249.

137. Vijayalakshmi AM, Ganesh VRR. Hemophagocytic syndrome associated with dengue hemorrhagic fever. Indian Pediatr. 2009;46(6):545.

138. Larbcharoensub N, Aroonroch R, Kanoksil W, Leopairut J, Nitiyanant P, Khositseth A, et al. Infectionassociated hemophagocytic syndrome among patients with dengue shock syndrome and invasive aspergillosis: a case series and review of the literature. Southeast Asian J Trop Med Public Health. 2011;42(5):1106-12.

139. Tan LH, Lum LCS, Omar SFS, Kan FK. Hemophagocytosis in dengue: comprehensive report of six cases. J Clin Virol. 2012;55(1):79-82.

140. Sharp TM, Gaul L, Muehlenbachs A, Hunsperger E, Bhatnagar J, Lueptow R, et al. Fatal hemophagocytic lymphohistiocytosis associated with locally acquired dengue virus infection: New Mexico and Texas, 2012. MMWR Morb Mortal Wkly Rep. 2014;63(3):49-54.

141. Raju S, Kalyanaraman S, Swaminathan K, Nisha A, Praisid S. Hemophagocytic lymphohistiocytosis syndrome in dengue hemorrhagic fever. Indian J Pediatr. 2014 Apr 15. Epub ahead of print. doi:10.1007/ s12098-014-1425-4

142. Ellis EM, Pérez-Padilla J, González L, Lebo E, Baker C, Sharp T, et al. Unusual cluster in time and space of dengue-associated hemophagocytic lymphohistiocytosis In Puerto Rico. Blood. 2013;122(21):3497.
143. Jordan MB, Allen CE, Weitzman S, Filipovich AH, McClain KL. How I treat hemophagocytic lymphohistiocytosis. Blood. 2011;118(15):4041-52.

144. Tan S-S, Bujang MA. The clinical features and outcomes of acute liver failure associated with dengue infection in adults: a case series. Braz J Infect Dis. 2013;17(2):164-9.

145. Kumarasena RS, Mananjala Senanayake S, Sivaraman K, de Silva AP, Dassanayake AS, Premaratna R, et al. Intravenous $\mathrm{N}$-acetylcysteine in dengue-associated acute liver failure. Hepatol Int. 2010;4(2):533-4.

146. Lim G, Lee JH. N-acetylcysteine in children with dengue-associated liver failure: a Case Report. J Trop Pediatr. 2012;58(5):409-13.

147. Senanayake M, Jayamanne M, Kankananarachchi I. $\mathrm{N}$-acetylcysteine in children with acute liver failure complicating dengue viral infection. Ceylon Med J. 2013;58(2):80-2.

148. Penafiel A, Devanand A, Tan HK, Eng P. Use of molecular adsorbent recirculating system in acute liver failure attributable to dengue hemorrhagic fever. J Intensive Care Med. 2006;21(6):369-71.

149. Cam BV, Tuan DT, Fonsmark L, Poulsen A, Tien NM, Tuan HM, et al. Randomized comparison of oxygen mask treatment vs. nasal continuous positive airway pressure in dengue shock syndrome with acute respiratory failure. J Trop Pediatr. 2002;48(6):335-9.

150.• Yacoub S, Wertheim H, Simmons CP, Screaton G, Wills B. Cardiovascular manifestations of the emerging dengue pandemic. Nat Rev Cardiol. 2014;11(6):335-45.

A timely update of established vascular effects of dengue infection as well as survey of the emerging cardiac manifestations.

151. Lateef A, Fisher DA, Tambyah PA. Dengue and relative bradycardia. Emerg Infect Dis. 2007;13(4):650-1.

152. Yacoub S, Griffiths A, Chau TTH, Simmons CP, Wills B, Hien TT, et al. Cardiac function in Vietnamese patients with different dengue severity grades. Crit Care Med. 2012;40(2):477-83.

153. Yadav DK, Choudhary S, Gupta PK, Beniwal MK, Agarwal S, Shukla U, et al. The Tei index and asymptomatic myocarditis in children with severe dengue. Pediatr Cardiol. 2013;34(6):1307-13.

154. Marques N, Gan VC, Leo Y-S. Dengue myocarditis in Singapore: two case reports. Infection. 2013;41(3):709-14.

155. Mahmood S, Nabeel H, Hafeez S, Zahra U, Nazeer H. Seroprevalence of dengue IgG antibodies among healthy adult population in Lahore. Pak ISRN Trop Med. 2013;2013:1-6.

156. Wilder-Smith A. Dengue infections in travellers. Paediatr Int Child Health. 2012;32 Suppl 1:28-32.

157. Simmons CP, Farrar J. Changing patterns of dengue epidemiology and implications for clinical management and vaccines. PLoS Med. 2009;6(9):e1000129.

158. Leo Y-S, Thein TL, Fisher DA, Low JG, Oh HM, Narayanan RL, et al. Confirmed adult dengue deaths in Singapore: 5-year multi-center retrospective study. BMC Infect Dis. 2011;11:123. 